\title{
Caracterização de manifestações patológicas em estações elevatórias e de tratamento de esgotos
}

O sistema de esgotamento sanitário e seus componentes são essenciais para o desenvolvimento da infraestrutura e saneamento e da qualidade de vida da população. As estruturas integradas ao funcionamento desse sistema possuem características próprias inerentes ao meio em que estão inseridas, sendo ambientalmente agressivos. A facilidade no desenvolvimento de patologias, aliada à falta de manutenção provocam diversos danos aos processos operacionais e relacionados ao tratamento de efluentes. Se previstos em projeto e tratados de forma preventiva, os gastos e energia dispendidos com estes problemas podem ser reduzidos do que se foram tratados de forma remediada. Utilizando classificação visual com a análise de registros fotográficos, objetivou-se identificar e classificar as patologias recorrentes em estações elevatórias (EE's) e de tratamento de esgotos (ETE's), levando em consideração sua origem (construtiva, funcional, acidental ou natural), intensidade (estética, funcional ou estrutural) e frequência. Constatou-se que a maior parte das patologias foram adquiridas, devido à classe de agressividade do ambiente, apresentando percentuais de $78,48 \%$ e $47,83 \%$, trazendo danos estruturais das construções na faixa de $43,90 \%$ e $83,33 \%$ em ETE's e EE's respectivamente. Por meio de fator característico para classificação de relevância, pode-se concluir que as ETE's são mais suscetíveis à danos de maior gravidade, atingindo com maior intensidade o sistema, em comparação às EE's.

Palavras-chave: Estações de Esgotos; Patologia adquiridas; Saneamento Ambiental; Tratamento de Efluentes.

\section{Characterization of pathological manifestations in pumping and sewage treatment plants}

\begin{abstract}
The sewage system and its components are essential for the development of infrastructure and sanitation and the quality of life of the population. The structures integrated to the operation of this system have their own characteristics inherent to the environment in which they are inserted, being environmentally aggressive. The ease in the development of pathologies, coupled with the lack of maintenance causes several damages to the operational processes and related to the treatment of effluents. If foreseen in the project and treated in a preventive way, the expenses and energy spent with these problems can be reduced than if they were treated in a remedied way. Using visual classification with the analysis of photographic records, the objective was to identify and classify recurrent pathologies in pumping stations (EE's) and sewage treatment plants (ETE's), taking into account their origin (constructive, functional, accidental or natural), intensity (aesthetic, functional or structural) and frequency. It was found that most of the pathologies were acquired, due to the class of aggressiveness of the environment, with percentages of $78.48 \%$ and $47.83 \%$, bringing structural damage to buildings in the range of $43.90 \%$ and $83.33 \%$ in ETE's and EE's respectively. By means of a characteristic factor for the classification of relevance, it can be concluded that TEE's are more susceptible to more serious damage, reaching the system with greater intensity, compared to EE's.
\end{abstract}

Keywords: Sewerage stations; Acquired pathology; Environmental sanitation; Wastewater treatment.

Topic: Engenharia Sanitária

Reviewed anonymously in the process of blind peer.
Received: 02/12/2020

Approved: $22 / 12 / 2020$
Diogo Botelho Correa de Oliveira (it

Universidade de Pernambuco, Brasil

http://lattes.cnpq.br/2647295852254445

http://orcid.org/0000-0003-1556-5664

diogobotelhocorrea@gmail.com

Paula Olivia de Belo (iD

Universidade de Pernambuco, Brasil

http://lattes.cnpq.br/2406756045896620

http://orcid.org/0000-0002-0869-9835

p.oliviadebelo@gmail.com

Willames de Albuquerque Soares (iD)

Universidade de Pernambuco, Brasil

http://lattes.cnpq.br/8129166589399635

http://orcid.org/0000-0003-3268-7241

was@poli.br

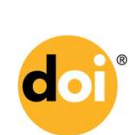

DOI: 10.6008/CBPC2179-6858.2020.007.0024
Eliana Cristina Barreto Monteiro (iD

Universidade de Pernambuco, Brasil

http://lattes.cnpq.br/3808888967301263

http://orcid.org/0000-0003-0842-779X

eliana@poli.br
Referencing this:

OLIVEIRA, D. B. C.; BELO, P. O.; SOARES, W. A.; MONTEIRO, E. C. B.. Caracterização de manifestações patológicas em estações elevatórias e de tratamento de esgotos. Revista Ibero Americana de Ciências Ambientais, v.11, n.7, p.271-283, 2020. DOI: http://doi.org/10.6008/CBPC2179-6858.2020.007.0024 


\section{INTRODUÇÃO}

Um dos serviços de infraestrutura que impactam diretamente no bem-estar do indivíduo é o saneamento básico. Sua ausência ou precariedade causa problemas econômicos, ambientais, sociais e de saúde. O setor relacionado a este assunto, no Brasil, tem recebido maior atenção governamental e há uma quantidade significativa de recursos a serem investidos. Um dos resultados desses investimentos é a Região Metropolitana do Recife, que possui a maior Parceria Público-Privada (PPP) destinada a novas implantações, manutenção e operação do Sistema de Esgotamento Sanitário (SES). As estruturas que compõe esse sistema estão expostas a ambientes e agentes agressivos, com classe de agressividade elevada, tornando-as vulneráveis ao surgimento de patologias e redução do tempo de vida útil pela qual é projetada, representando uma ameaça aos investidores e profissionais da área (IDALGO, 2016).

Uma das razões para o estudo das patologias das estruturas é devido à necessidade de divulgação das manifestações patológicas mais incidentes, para fundamentar programas de manutenção e prevenção das mesmas, a fim de que quanto antes detectadas menores serão os custos para a recuperação dos elementos danificados (BASTOS et al., 2017). Os fenômenos patológicos apresentam manifestações de características e ocorrências bem definidas, fazendo com que seja possível realizar diagnósticos preliminares eficientes apenas por inspeção visual, entretanto, em outros casos é necessário verificar o projeto, investigar a estrutura e até a realização de ensaios, nos casos mais complexos (ARIVABENE, 2015).

Embora existam muitos estudos na área alertando sobre as manutenções preventivas e ao desenvolvimento correto dos projetos, ainda existem limitações para execução e implantação dos mesmos, visto que as estruturas apresentam desempenho insatisfatório devido às falhas involuntárias, imperícias, má utilização de materiais, envelhecimento natural sem manutenções periódicas e preventivas, não atendimento das recomendações das normas, interação com o meio ambiente, erros de projetos e dimensionamentos que contribuem para a degradação da estrutura (LORDSLEEM JUNIOR et al., 2017).

Além das citadas anteriormente, diversas manifestações podem surgir devido a existência de falhas de origens distintas, dentre as quais podem ser em qualquer uma das seguintes etapas: planejamento, concepção do projeto, execução, utilização e ausência de manutenção (SANTOS et al., 2017).

Visando contribuir para o histórico das patologias, a classificação das manifestações encontradas quanto a: sua natureza, nível de impacto, redução de durabilidade e eventual dano, fornece um melhor entendimento objetivando ressaltar a importância do tema estudado.

Nesse contexto, destaca-se a durabilidade das estruturas, que está intimamente relacionada com a vida útil que é desejada. Apesar disto, existem dois fatores relevantes que interferem nesta questão: as propriedades do concreto como material heterogêneo em proporção adequada de cimento, agregados, água e adições e/ou aditivos, e a interação com o meio ambiente e suas condições de contorno, por vezes consideradas condições adversas de agressividade ambiental.

O concreto numa estação de tratamento de esgoto (ETE) ou estação elevatória de esgoto (EEE) está sujeito a ação do esgoto doméstico, sendo um ambiente de agressividade muito forte, classe IV (NBR:6118 - 
ABNT, 2014). Sendo assim, o responsável pela sua deterioração é o gás sulfídrico $\left(\mathrm{H}_{2} \mathrm{~S}\right)$ e o anidrido carbônico (CO2) que favorece a formação do ácido sulfúrico biogênico $\left(\mathrm{H}_{2} \mathrm{SO}_{4}\right)$ devido ao microclima no interior da estrutura de concreto. No que se diz a respeito dos elementos estruturais (pilares, vigas e lajes), observa-se o elevado índice de degradação, principalmente à ação da corrosão de armaduras e fissuras provocadas pelas movimentações de origem estrutural (KUDLANVEC JUNIOR et al., 2018).

Além disso, os ambientes de clima característicos tropicais são bastante suscetíveis ao desenvolvimento de diversas patologias que prejudicam o funcionamento corretos desses elementos, gerando maiores custos e reduções nos intervalos de intervenções físicas, prejudicando modelos sustentáveis de operação desse tipo de SES (SILVEIRA et al., 2019).

Diante do exposto o presente trabalho tem como objetivo principal caracterizar as manifestações patológicas mais frequentes encontradas em algumas estruturas que compõe o sistema de esgotamento sanitário de alguns municípios pertencentes a Região Metropolitana do Recife.

\section{MATERIAIS E MÉTODOS}

O desenvolvimento deste trabalho baseou-se em levantamento de dados sobre as manifestações patológicas mais incidentes encontradas nas estações elevatórias e de tratamento de esgoto na Região Metropolitana do Recife (RMR).

Considerada um espaço privilegiado da região Nordeste devido a sua proximidade ao mercado mundial, exerce uma importância econômica e política, foi uma das primeiras metrópoles constituídas no Brasil, caracteriza-se como o segundo maior aglomerado urbano do Nordeste e o sexto do Brasil (SILVA et al., 2019).

As estruturas do estudo se localizam na faixa do litoral pernambucano. Esta é uma região de clima tropical, quente e úmido, possuindo temperaturas médias que variam entre $298 \mathrm{~K}$ e $303 \mathrm{~K}$. Normalmente os meses onde a temperatura fica mais elevada são outubro, novembro e dezembro. Em junho, julho e agosto, durante o período de inverno, que na região apresenta os maiores índices pluviométricos, a média da temperatura é de 296 K. A RMR possui média acumulada anual de $2050 \mathrm{~mm}$ de chuva, sendo a zona de maior pluviosidade do litoral nordestino. Geralmente, os meses de outubro a fevereiro são muito secos, com médias pluviais entre 50 e 100 mm mensais, e a partir de março é onde começa o período chuvoso. No mês de junho é registrada a precipitação máxima, que é superior à $600 \mathrm{~mm}$ acumulados (OLIVEIRA et al., 2020).

Dentro do estudo foram 12 diferentes estruturas que compõem o SES, sendo compostas por 6 estações elevatórias e 6 estações de tratamento da RMR, onde a distribuição espacial dos munícipios inseridos pode ser visualizada na Figura 1. Utilizaram-se 52 registros fotográficos de diferentes patologias, separadas por município e tipo de estrutura de saneamento (EEE ou ETE).

A metodologia de análise se desenvolveu nas seguintes etapas: Inspeção preliminar, Identificação e diagnóstico, e Classificação por fator de relevância da patologia. 


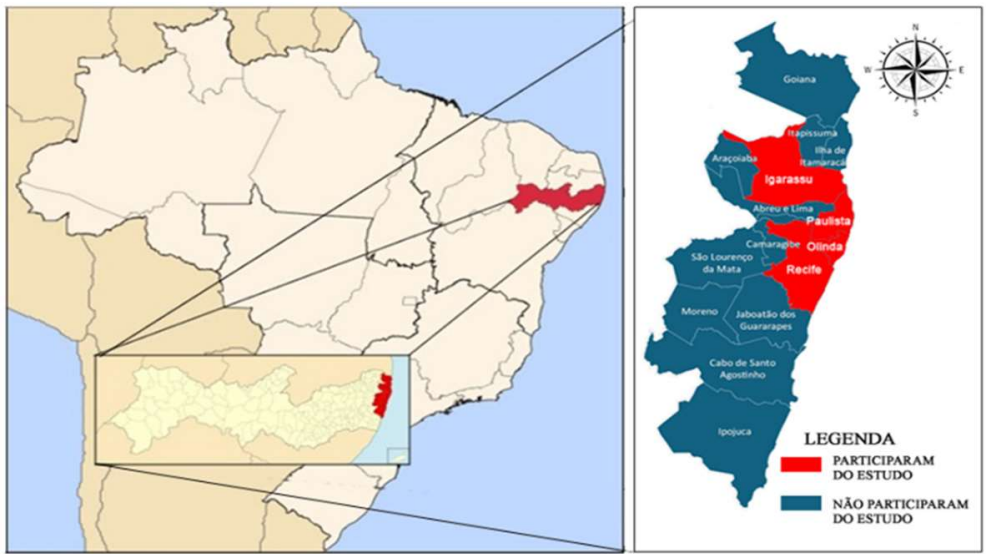

Figura 1: Municípios da RMR que participaram do estudo.

\section{Inspeção Preliminar}

Consistiu na avaliação do registro fotográfico de todas as anomalias existentes nas estruturas. Diante disso, foi realizado a identificação da manifestação encontrada e o seu sintoma patológico, além da sua provável origem.

\section{Identificação e diagnóstico}

Foram atribuídas identificações distintas e singulares para cada tipo de patologia identificada nas diversas estruturas, visando a qualificação e quantificação dos dados obtidos, de modo que fossem geradas as frequências para análises estatísticas. Após a identificação de cada patologia, o diagnóstico consistiu em avaliar e classificar o seu nível de degradação, considerando que uma determinada patologia pode apresentar diferentes níveis de impacto em estruturas específicas, a depender do local e da forma que ela se comporta e do estágio de degradação em que se encontra. Sendo assim, as divisões foram classificadas, quanto ao impacto, em:

Danos estéticos: Verificado por meio de desconforto visual e aparente (Exemplos: bolor, manchas pela ação de agentes externos).

Danos funcionais: Realizada a inspeção visual, verifica-se a perda parcial de desempenho e finalidade (Exemplos: junta fria, eflorescências).

Danos estruturais: Observado por meio de inspeção visual o comprometimento da segurança da estabilidade (Exemplos: Trincas, Corrosão).

Em seguida, para que fosse possível apresentar hipóteses dos surgimentos das patologias, foi utilizado umas das classificações da Norma de Inspeção Predial Nacional 2012, que classifica a origem das patologias da seguinte maneira (IBAPE, 2012):

Endógenas ou construtivas: Originadas da própria edificação (projeto, materiais e execução).

Adquiridas ou funcionais: Originada da degradação de sistemas construtivos pelo envelhecimento natural e, consequente, término da vida útil.

Acidentais ou exógenas: Originada de fatores externos, provocadas por terceiros.

Naturais: Originada de fenômenos da natureza. 


\section{Classificação por fator de relevância}

As localidades estudadas podem ser de dois tipos: estações de tratamento e estações elevatórias de esgoto. As estações de tratamento (ETE) são os locais destinados ao tratamento do esgoto. Seu funcionamento é constituído basicamente por tanques de concreto armado, decantadores e defletores de gases, entre outras estruturas de apoio para a sua operação e funcionamento. Já as estações elevatórias (EEE) são responsáveis pela coleta de esgoto e destinação até a ETE, em geral são constituídos por poços úmidos, caixas de areia e tanques de concreto, além do conjunto de bombas, que contribuem para o excesso de vibração nas estruturas.

Uma patologia encontrada em uma ETE irá apresentar maiores riscos e impactos ao Sistema de Esgotamento Sanitário (SES) do que caso encontrada na EEE. Para isso, foi adotado dois fatores de relevância, um associado ao tipo de estrutura de saneamento e outro para a intensidade da patologia quanto ao dano (Tabela 03).

Para o cálculo do fator de relevância geral (F), para ETE ou EEE, utiliza-se a seguinte equação:

$$
F=\left(\frac{N_{1} D E+N_{2} D F+N_{3} D T}{N_{1}+N_{2}+N_{3}}\right)
$$

Onde, $N_{1}$ : número de patologias por danos estéticos; $N_{2}$ : número de patologias por danos funcionais; $N_{3}$ : número de patologias por danos estruturais; $D E$ : fator de risco por dano estético; $D F$ : fator de risco por dano funcional; $D T$ : fator de risco por dano estrutural.

Após o cálculo de $F$, que obrigatoriamente será um valor entre 0 e 1 , podemos concluir que quanto mais próximo de 1, maior é o grau de impacto das manifestações patológicas na unidade, afetando a vida útil e durabilidade da estrutura, o que requer uma devida atenção para a manutenção e correção dos problemas patológicos.

Tabela 1: Fator de relevância.

\begin{tabular}{|l|l|l|l|}
\hline Fator de Risco & Tipo de estrutura de saneamento & Intensidade por dano & Correspondente numérico \\
\hline \multirow{4}{*}{ I } & \multirow{3}{*}{ ETE } & Dano estético & 0,2 \\
\cline { 3 - 4 } & & Dano funcional & 0,5 \\
\cline { 3 - 4 } & & Dano estrutural & 1 \\
\hline \multirow{3}{*}{$I$} & \multirow{3}{*}{ EEE } & Dano estético & 0,1 \\
\cline { 3 - 4 } & & Dano funcional & 0,25 \\
\cline { 3 - 4 } & & Dano estrutural & 0,5 \\
\hline
\end{tabular}

\section{RESULTADOS E DISCUSSÃO}

Identificou-se a presença de patologia classificada como junta fria nas paredes do tanque séptico, que favorece as infiltrações do efluente para a área externa, como o fluxo contrário da água oriunda do lençol freático para o interior da estrutura, ocasionando danos funcionais (Figura 2). Sua provável formação devese a um problema patogênico formado durante a concretagem em etapas das paredes sem o devido tratamento para prevenir este acontecimento.

O bolor na parte inferior da caixa de reunião da entrada da estação de tratamento de esgotos ocasiona danos estruturais devido ao seu estado avançado (Figura 3). Sua provável origem adquirida devese a infiltração do líquido que percola pela estrutura de concreto, devido à ausência de impermeabilização 
ou camada de sacrifício na parte interna do tanque, que fica em contato direto com o afluente bruto. Sua formação também é favorecida pela quantidade de matéria orgânica existente no local e a ausência de incidência solar.

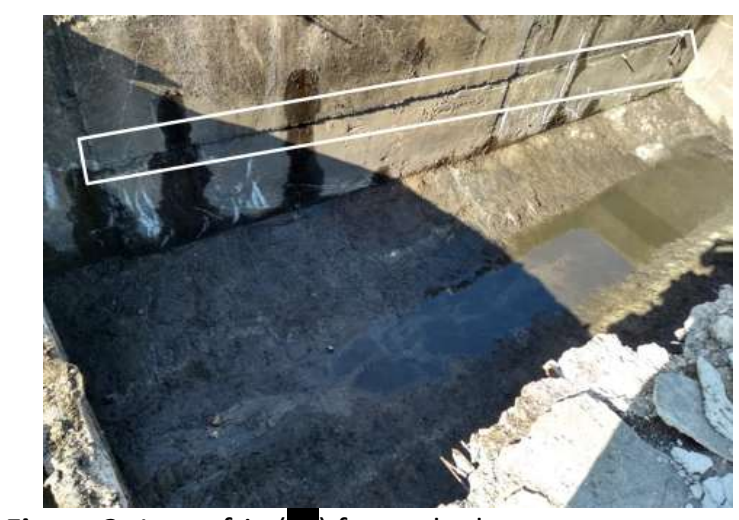

Figura 2: Junta fria ( $=$ formada durante concretagem de tanque séptico em Igarassu.

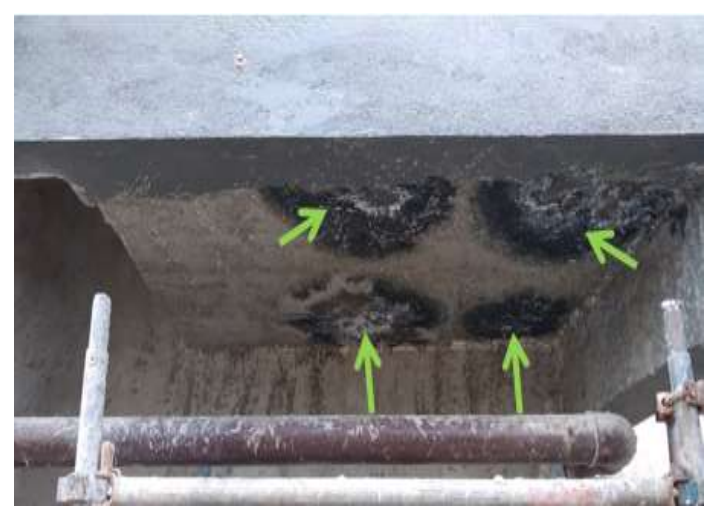

Figura 3: Bolor $(=)$ na caixa de reunião de entrada de afluente em ETE.

A presença do bolor nas paredes da caixa de areia, acrescida ao ataque dos sulfatos presente no afluente trazem danos funcionais à estrutura, já que contribuem para a deterioração e redução da vida útil, prejudicando o funcionamento eficiente na etapa do tratamento preliminar da ETE do município de Paulista (Figura 4). Com a ação contínua e a evolução dos danos decorrentes da ação do ataque de sulfatos, os quais são provenientes de um problema adquirido por infiltrações, fez com que a junta de movimentação existente sofresse uma expansão, sendo assim um dano estrutural na parte inferior da laje de fundo da caixa de reunião (Figura 5).

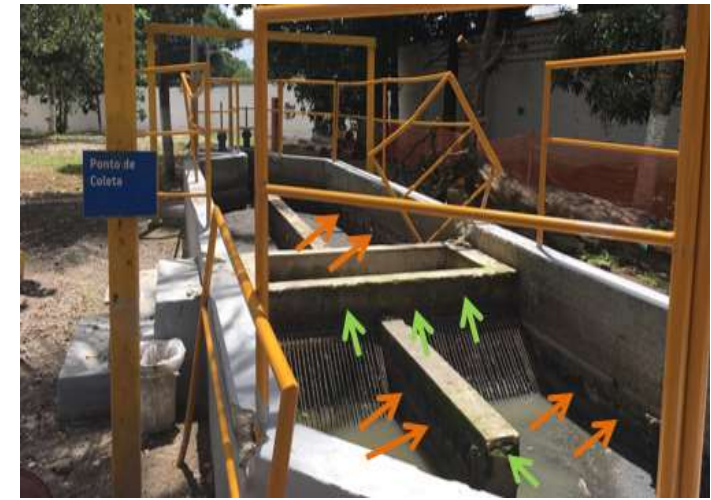

Figura 4: Bolor $(=)$ e a ação do ataque de sulfatos $(=)$ no sistema preliminar (caixa de areia).

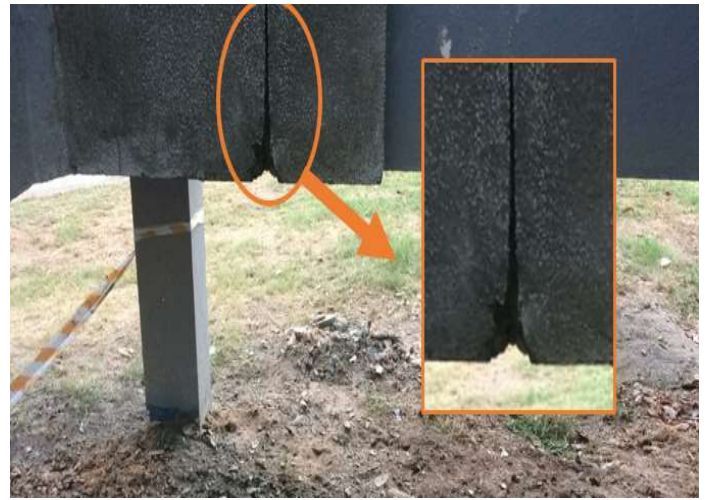

Figura 5: Ataque de sulfatos ( $=$ na caixa de reunião de ETE.

Por outro lado, é possível observar o dano estrutural de natureza adquirida causado pela ação dos sulfatos que contribuíram para a corrosão da armadura existente na laje superior de um anexo da ETE (Figura 6). Neste caso não houve ação direta do esgoto em tratamento, realçando a suscetibilidade de todos os tipos de estruturas em adquirirem problemas decorrentes do uso e da falta de manutenção preventiva.

Outra patologia bastante comum, em ambientes de alta agressividade ou não, são as fissuras. Destaca-se como exemplo, os danos estéticos no muro externo da estação elevatória, que podem ter sidos originadas devido à ausência de amarração ou a sua má execução entre as alvenarias, sendo um problema construtivo (Figura 7). Como se trata de uma EE, as vibrações excessivas oriundas das bombas de recalque 
contribuem consideravelmente para o surgimento desta patologia. Pelo seu tamanho e profundidade não oferecem risco à estrutura.

Ao contrário das anteriores (Figura 7), as fissuras encontradas são horizontais e tem sua origem em problemas construtivos, devido ao alteamento indevido, onde sua parte inferior foi realizada em concreto e a superior em alvenaria de vedação, causando problemas funcionais na caixa de saída do efluente tratado da ETE (Figura 8).

As manchas superficiais causadas por ação de agentes externos, que tem origem natural e representam danos estéticos nos biodigestores. Seu tratamento é bastante simples, mas possui periodicidade maior do que quando são problemas de tipo funcional ou estrutural (Figura 9).

Também foram encontradas a presença de manchas causadas pela ação de agentes externos (chuvas) e fissuras, provocadas por causas naturais e problemas construtivos respectivamente, juntas estas patologias trazem danos funcionais nas paredes externas e internas nos valos da ETE do município de Paulista (Figura 10).

Devido à caracterização do ambiente agressivo, pela proximidade do mar e a falta de manutenção periódica, os danos estéticos são representados através de corrosão no portão de entrada e das manchas causadas pela ação dos agentes externos como a chuva no muro de entrada, estas manifestações têm sua origem adquirida na oxidação e natural nas manchas (Figura 11).

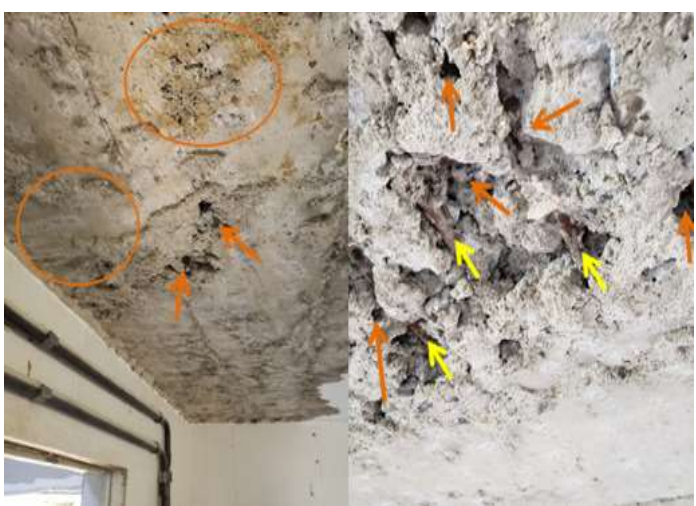

Figura 6: Corrosão ( $\rightarrow$ ) e ação pelo ataque dos sulfatos $(=)$ encontrados na laje superior de estrutura da ETE.

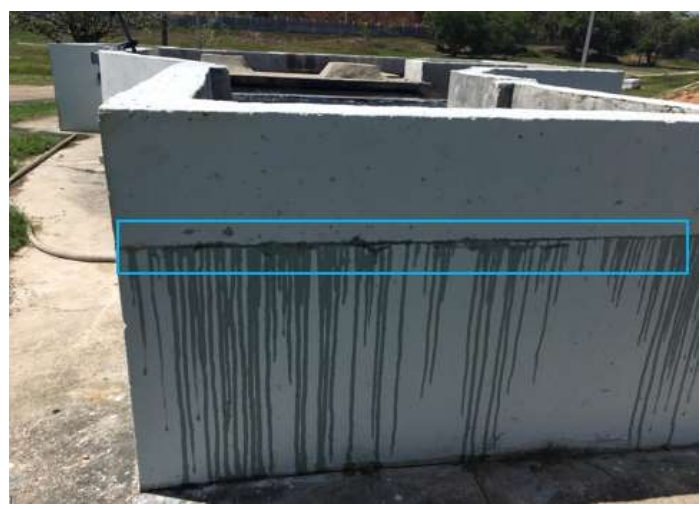

Figura 8: Fissuras ( $=$ na caixa de saída do afluente.

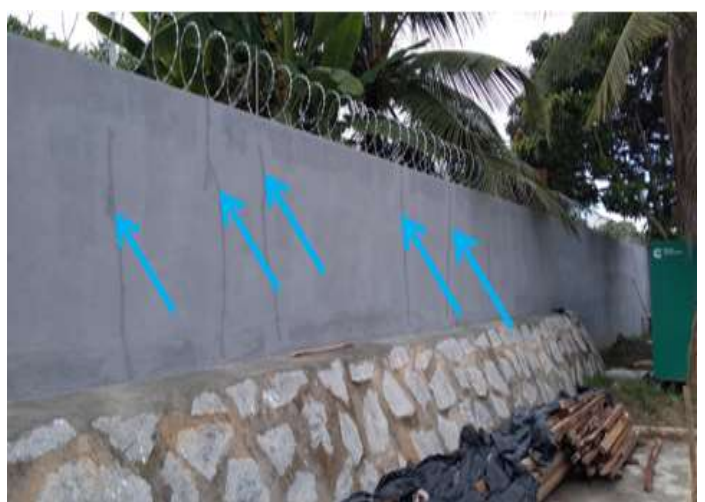

Figura 7: Fissuras $(=)$ no muro externo de EE.

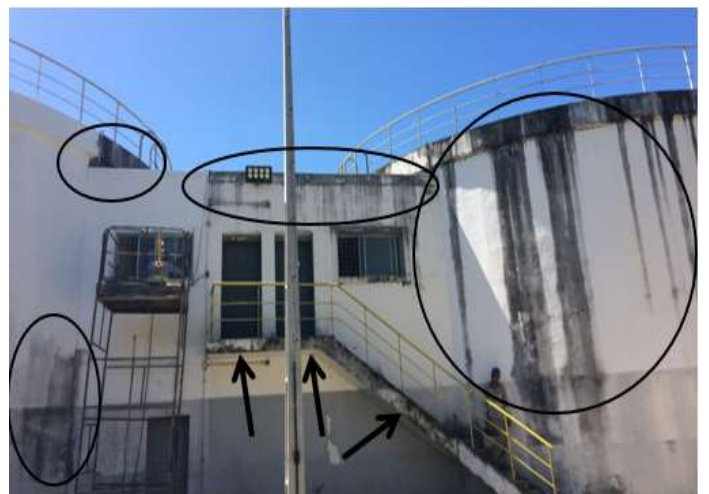

Figura 9: Manchas pela ação de agentes externos (=) em biodigestores. 


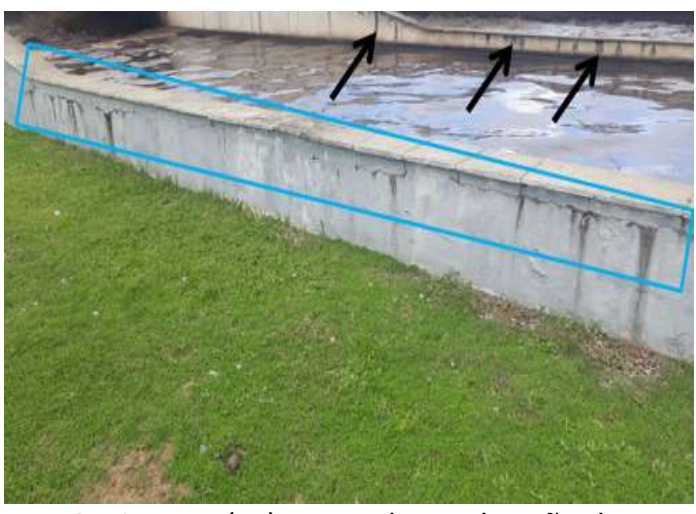

Figura 10: Fissuras $(=)$ e manchas pela ação de agentes externos $(=)$ nas paredes internas e externas dos valos de oxidação.

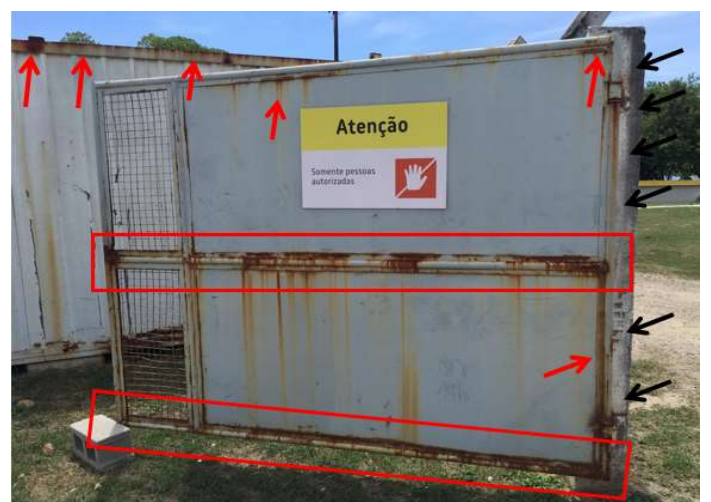

Figura 11: Manchas pela ação de agentes externos $(=)$ e oxidação $(=)$ em portão metálico.

Verifica-se além da presença de bolor, as fissuras e manchas por oxidação que ocorrem devido à elevada umidade e ausência de exposição solar, que contribuem para formar um conjunto de patologias com sua origem adquirida devido ao ambiente, traz danos funcionais nas paredes externas dos valos, afetando levemente a eficiência da operação do sistema (Figura 12).

Já as manchas superficiais de origem natural causadas por ação de agentes externos (chuvas), a presença de bolor e descolamento por empolamento, que tem sua origem devido ao funcionamento do sistema, juntas as patologias encontradas causam danos estéticos na caixa do barrilete da estação elevatória (Figura 13).

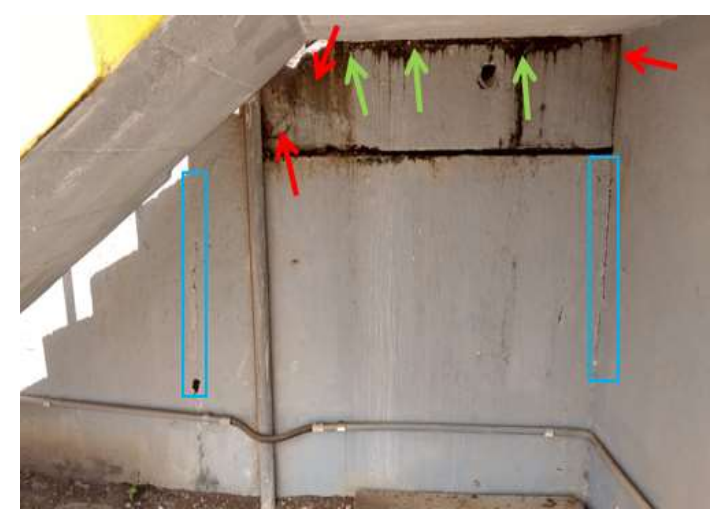

Figura 12: Fissuras $(=)$, bolor $(=)$ e manchas por oxidação $(=)$ na laje inferior dos valos de oxidação.

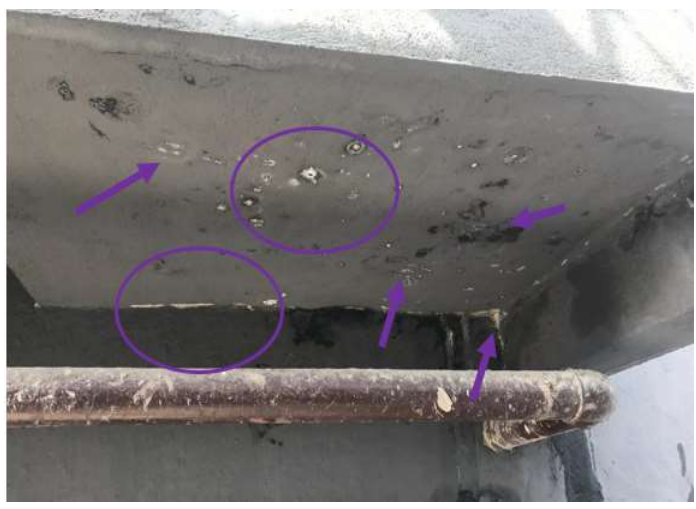

Figura 14: Eflorescência $(=)$ encontrada na parte inferior da laje da caixa de areia.

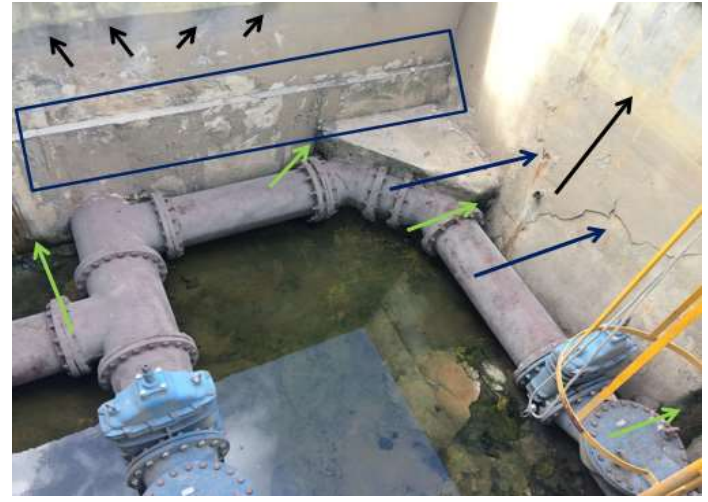

Figura 13: Descolamento por empolamento $(=)$, manchas pela ação de agentes externos $(=)$ e bolor $(=)$ na caixa do barrilete de EE.

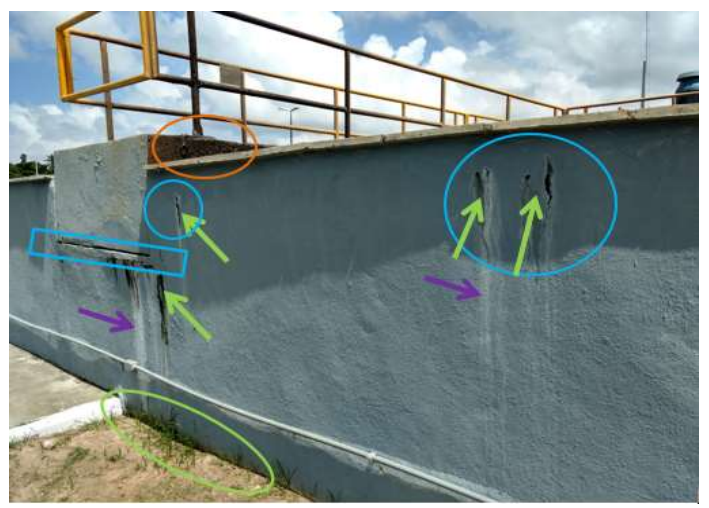

Figura 15: Bolor $(=)$, ataque de sulfatos $(=)$, fissuras $(=$ ) e o fenômeno da eflorescência $(=)$ nas paredes dos valos de oxidação. 
A eflorescência foi originada devido a infiltrações ocasionadas pelo funcionamento das estruturas de tratamento, caixa de areia da estação (Figura 14) e valos de oxidação (Figura 15), sendo assim, classificado como um dano estrutural na primeira e funcional na segunda. Nos valos ainda podem ser identificadas a presença de bolor, fissuras e o ataque de sulfatos. Sendo o surgimento destas patologias ocasionados devido ao funcionamento e operação do sistema, sem as tratativas de proteção adequadas na fase de recuperação/construção da mesma.

Manchas superficiais por ação de agentes externos caracterizam novamente dano estético (Figura 16) e trincas, danos estruturais, devido ao recalque ocasionado pela demolição da laje da caixa do barrilete da $\mathrm{EE}$, sendo assim um dano estrutural e de origem acidental. Encontra-se também a corrosão e manchas por oxidação, provocando danos estruturais na tubulação ferro fundido de chegada do efluente (Figura 17). Sua origem pode ser classificada como adquirida, visto que há a incidência do contato direto com o esgoto.

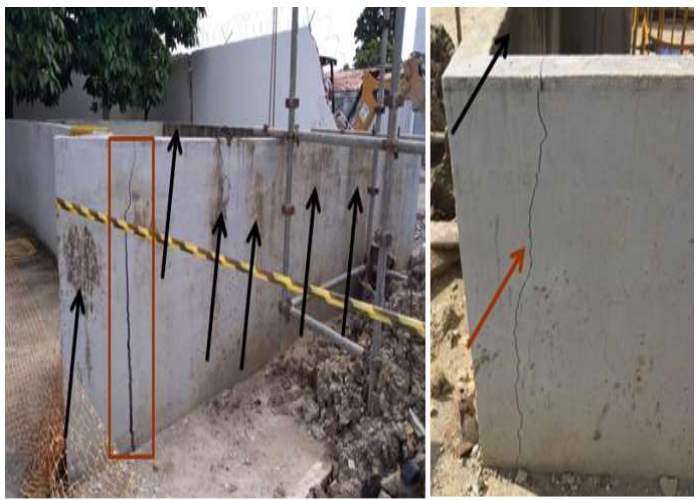

Figura 16: Trincas (=) e manchas pela ação de agentes externos $(=)$ na parede da caixa do barrilete de EE.

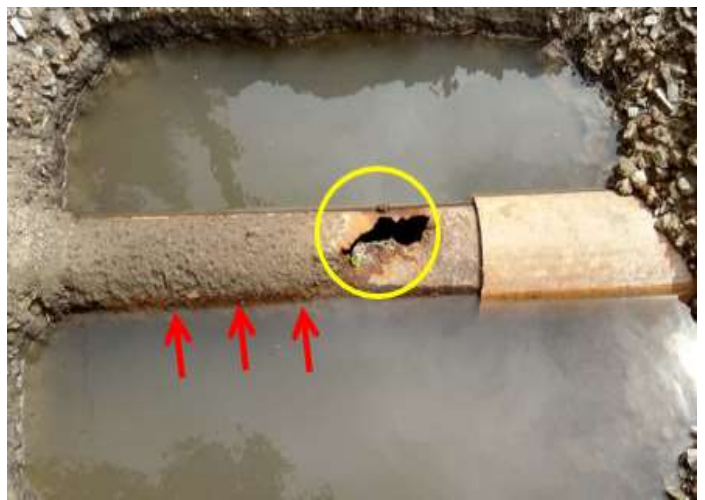

Figura 17: Corrosão ( ) e manchas por oxidação (=) na tubulação de chegada do efluente.

A abrasão pode ser observada pelo descolamento da superfície de concreto em conjunto com a ação do ataque de sulfatos, o fenômeno da eflorescência e as manchas da oxidação pela corrosão, encontrada na caixa de entrada da ETE (Figura 18) e a perda de aderência da armadura devido ao efeito de corrosão no pilar da estrutura da lagoa de decantação da ETE acarretando em um dano estrutural com uma provável origem congênita na escolha e definição do traço do concreto a ser utilizado (Figura 19).

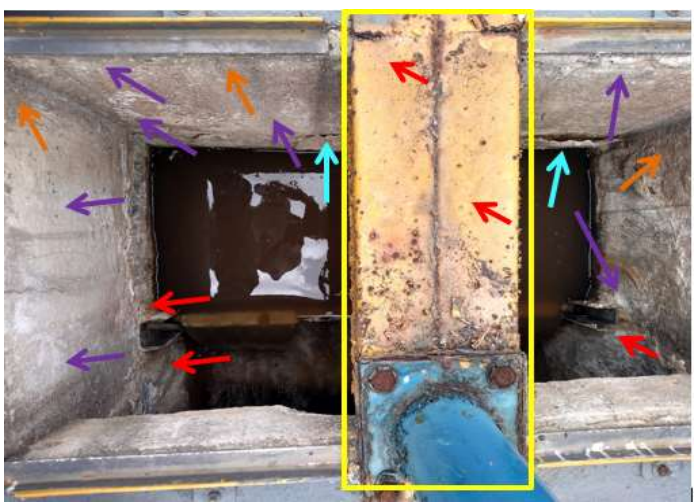

Figura 18: Abrasão (=), corrosão $(=)$, oxidação $(=)$, eflorescência $(=)$ e ação do ataque de sulfatos $(=)$ na caixa de saída de ETE.

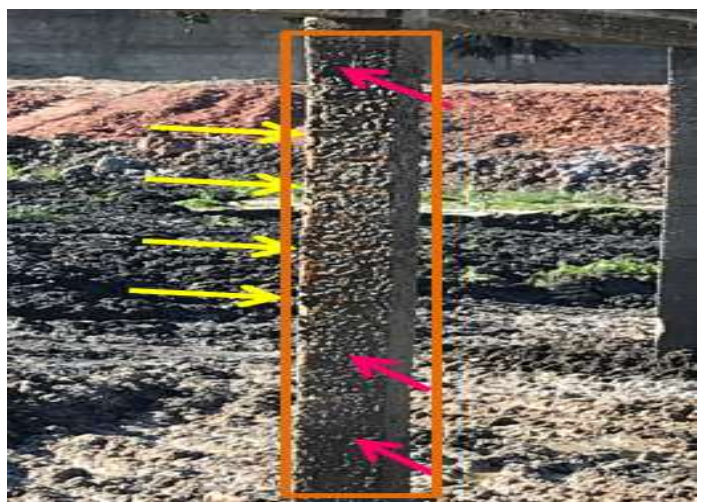

Figura 19: Lixiviação (=), ataque de sulfatos $(=)$ e corrosão $(-$ ) na laje inferior da caixa de reunião da ETE.

Uma patologia bastante comum na RMR e de graves consequências é a Reação Álcalis-Agregado. 
Diante da metodologia utilizada, existiu forte suspeita que pode ser diagnosticada como suscetível aos ataques por sulfatos, devido à presença de fissuras não uniformes, o que torna inviável a diferenciação entre as manifestações sem a utilização de ensaios (HELENE et al., 2016; RIBEIRO et al., 2019). Esta patologia junto com a presença de outras manifestações como bolor e corrosão, foram adquiridas pelo meio agressivo em que se encontram e trazem danos funcionais na caixa de entrada do poço úmido de ETE (Figura 20). Nota-se a presença de manchas causadas pela ação de agentes externos, de origem natural, além do descolamento com pulverulência na casa de apoio de EE com origem do tipo adquirida (Figura 21).

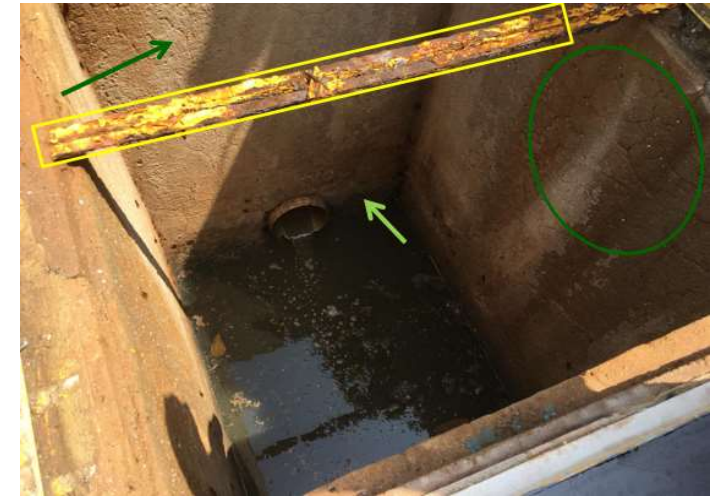

Figura 20: Presença de bolor $(=)$, corrosão $(=)$ e Reação Álcalis-Agregado (=) na caixa de entrada do poço úmido da ETE do município de Recife.

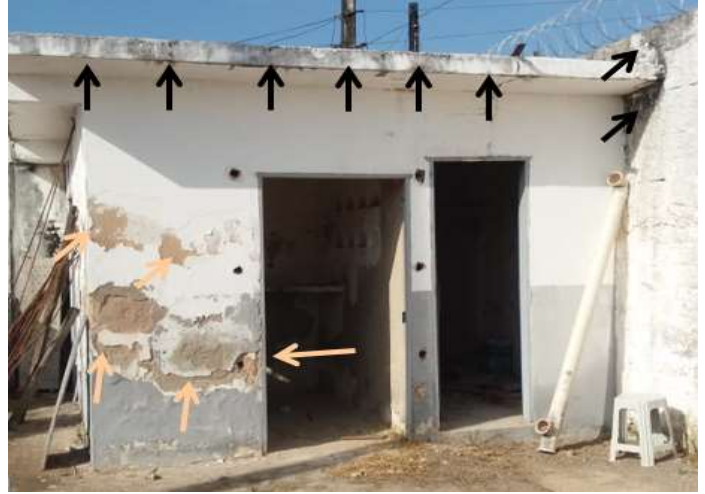

Figura 21: Presença de manchas pela ação de agentes externos (=) e descolamento com pulverulência ( ) na casa de apoio de EE.

As incidências das patologias quanto aos danos podem ser visualizadas para as ETE's (Figura 22) e EE's (Figura 23). Observa-se maior distribuição entre as estações de tratamento, onde a frequência é crescente quanto à gravidade do prejuízo e risco que os problemas causam. Os danos estruturais tiveram maior incidência nos dois casos, reforçando a gravidade que o ambiente agressivo pode impactar nas estruturas pertencentes a ele, como também a necessidade de recuperação e reforço estrutural nessas localidades.

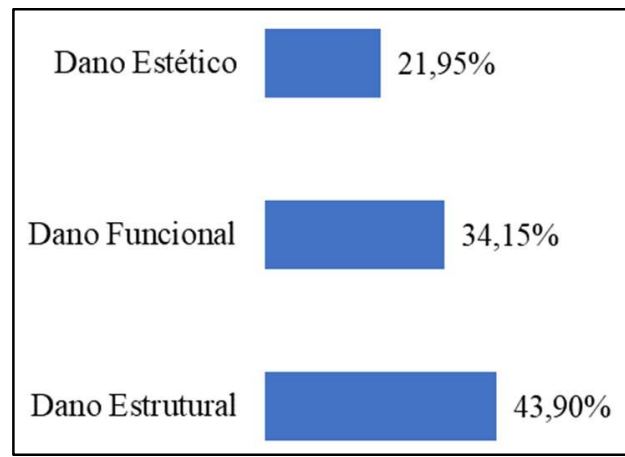

Figura 22: Impacto de danos nas ETE's.

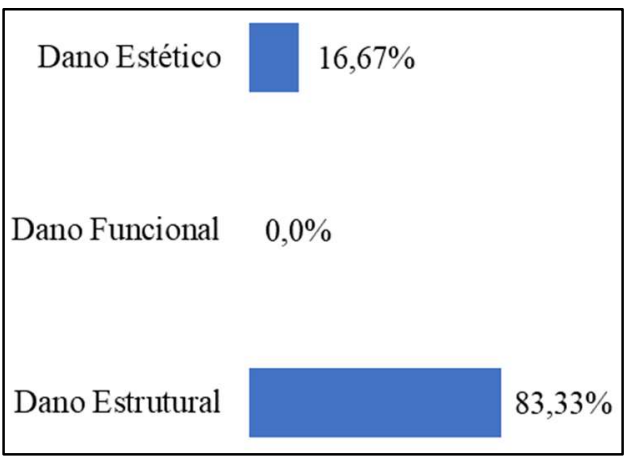

Figura 23: Impacto de danos nas EE's.

Para o fator de relevância, obteve-se 0,65 para as estações de tratamento e 0,17 para as elevatórias. O primeiro apresenta maior relevância, tanto pela sua importância no funcionamento do SES quanto à sua extensão física. Já as elevatórias, apesar da alta incidência de danos estruturais, não apresentaram o indicador de FR elevado. Isto indica que os complexos destinados ao tratamento dos efluentes necessitam de maior atenção e redirecionamento de recursos técnicos e financeiros para a sua conservação e operação 
do que em estações destinadas apenas ao bombeamento dos afluentes.

Tanto para ETEs quanto EEEs a principal origem das manifestações foi a adquirida (Figuras 24 e 25). Isto é decorrência do ambiente de agressividade muito forte e deterioração elevada, já que existe a alta produção de gases reagentes e o ataque de sulfatos às estruturas de concreto (reação entre os sulfatos presentes no afluente e os aluminatos presentes no concreto).

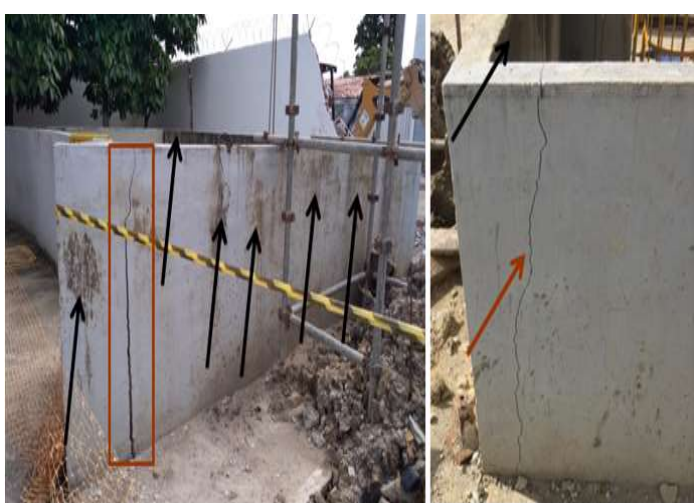

Figura 16: Trincas $(=)$ e manchas pela ação de agentes externos $(=)$ na parede da caixa do barrilete de EE.

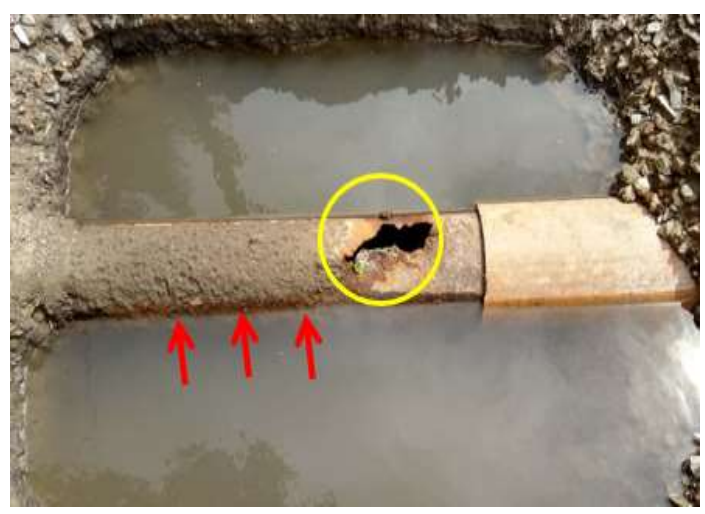

Figura 17: Corrosão $(=)$ e manchas por oxidação $(=)$ na tubulação de chegada do efluente.

As patologias de maiores recorrências (Figura 26) foram o bolor e as manchas pela ação de agentes externo, com percentuais próximos a $20 \%$, sendo em essência danos estéticos e de fácil tratativa, através de manutenções periódicas preventivas simples. A corrosão, eflorescência, fissuras e ataque por sulfatos também foram manifestações bastante presentes nessas estruturas, e suas correções podem gerar custos elevados devido à necessidade de realizar a parada no sistema em operação, que geram $42,8 \%$ das ocorrências. Isto de indica que quase metade das patologias encontradas sofrem influência direta do sistema em que se encontram, principalmente a corrosão e os ataques por sulfatos. Por outro lado, o descolamento por empolamento tanto pulverulência, RAA e junta fria foram as manifestações de menor incidência.

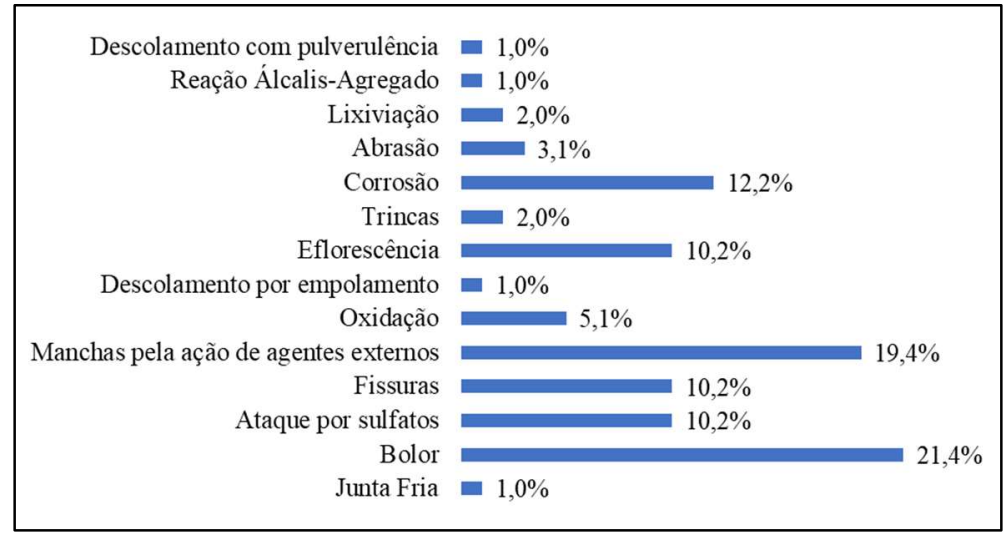

Figura 26: Ocorrência das patologias nas estruturas de saneamento.

As duas últimas são problemas mais custosos para tratativas, tendo em vista o cunho estrutural agregado a estes problemas, já as outras citadas são de simples correção e em sua maioria, prejudicam esteticamente a estrutura. De modo geral, a diversidade de patologias e o resultado encontrado já era o esperado conforme estudos realizados anteriormente, o que comprova a agressividade do meio em que as 
estruturas que compõe o sistema de saneamento estão inseridas, adquiridas devido a exposição aos gases formados no interior das estruturas, a ausência de manutenção e até problemas construtivos.

\section{CONCLUSÕES}

A necessidade do estudo das manifestações patológicas em estruturas de saneamento é uma situação que requer atenção devido ao fato que as mesmas apresentam desempenho e durabilidade aquém do que se espera em alguns anos de operação. Baseado na pesquisa realizada, pôde-se afirmar o ambiente de elevada classe de agressividade, confirmada com a alta incidência de patologias com configurações próprias em estágios específicos de impacto e deterioração da estrutura.

Em ambos os casos, ETE's e EE's, as patologias tiveram a maioria de suas origens decorrentes do meio em que se encontram, onde os maiores danos encontrados são de cunho estrutural e decorrentes da suscetibilidade do concreto ao desenvolvimento destes tipos de doenças. Diante da metodologia utilizada, existe certa limitação no que se diz a exata confirmação de algumas patologias, como ataque por sulfatos e reação álcalis-agregado, visto que ambas apresentam sintomas patológicos parecidos, somente diferenciados através da utilização de ensaios específicos e maior detalhamento na estrutura.

Por meio dos resultados obtidos, é confirmado que as estações de tratamento são mais vulneráveis ao desenvolvimento de patologias, devendo assim receberem maior atenção em implementações e operações de planos de manutenção, manutenções preventivas e monitoramento da unidade.

De modo geral, a prevenção das construções para este tipo de ambiente deve ser considerada como fator relevante e decisivo nas concepções de projetos e execução, desde a fase de elaboração do até a manutenção, a fim de garantir e prolongar a vida útil, durabilidade e operação dessas estruturas, proporcionando melhor otimização nos gastos com recuperações futuras.

\section{REFERÊNCIAS}

ABNT. Associação Brasileira de Normas Técnicas. NBR 6118: Projetos de estruturas de concreto. Rio de Janeiro: ABNT, 2014.

ARIVABENE, A. C.. Patologias em estruturas de concreto armado: Estudo de Caso. Revista ON-LINE IPOG, v.10, n.1, p.1-22, 2015.

BASTOS, H. C. N.; MIRANDA, M. Z.. Principais patologias em estruturas de concreto de pontes e viadutos: manuseio e manutenção das obras de arte especiais. Revista

Constituindo, v.9, p.93-101, 2017.

HELENE, P.; CARVALHO, M.; PACHECO, J.. Engineering field tests for álcali-aggregate reaction. Structural Concrete, v.18, n.2, p.349-355, 2016. DOI:

http://doi.org/10.1002/suco.201600090

IDALGO, B. G.. Estudo de critérios de projeto para prevenção de manifestações patológicas no concreto armado em obras de saneamento. Revista On-line IPOG, v.12, n.1, p.1-28, 2016.
KUDLANVEC JUNIOR, V.L.; CANALLE, R.; NUNES, T. K. L.; RESENDE, E. C. R. C.; SILVA, M. D. S. C.. Levantamento de manifestações patológicas em estação de tratamento de esgoto: estudo de caso em reator UASB. In: Simpósio Paranaense de Patologia das Construções, 3. Anais. Paraná, 2018. DOI: http://doi.org/10.4322/2526-7248.010

LORDSLEEM JUNIOR, A. C.; BATISTA FARO, H.. Descolamento de revestimento de fachada: estudo de caso. Revista ALCONPAT, v.7, n.2, p.148-159, 2017. DOI: http://doi.org/10.21041/ra.v7i2.126

IBAPE. Instituto Brasileiro de Avaliações e Perícias de Engenharia. Norma de Inspeção Predial Nacional. São Paulo, 2012.

OLIVEIRA, D. B. C.; SOARES, W. A.; HOLANDA, M. A. C. R.. Effects of Rainwater intrusion on an activated sludge sewer treatment system. Revista Ambiente e Água, v.15, n.3, p.112, 2020. DOI: http://doi.org/10.4136/ambi-agua.2497

RIBEIRO, D. V.; REY, R. O.. Avaliação dos agregados utilizados na região metropolitana de Salvador quanto à ocorrência de Reatividade Álcalis-Agregado (RAA). Revista ALCONPAT, v.9, 
n.2, p.185-199, 2019. DOI:

http://doi.org/10.21041/ra.v9i2.326

SANTOS, C. R. B.; SILVA, D. L.; NASCIMENTO, I. M. S..

Incidência de manifestações patológicas em edificações

residenciais na Região Metropolitana do Recife (RMR).

Revista de Engenharia e Pesquisa Aplicada, v.2, n.3, p.76-

86, 2017. DOI: http://doi.org/10.25286/repa.v2i3.690

SILVA, M. N.; LAPA, T. A.. O transporte público coletivo sob a lógica da produção capitalista do espaço: uma análise do serviço de ônibus na Região Metropolitana do Recife. Caderno Metrópole, v.21, n.45, p.511-530, 2019. DOI: http://doi.org/10.1590/2236-9996.2019-4507

SILVEIRA, V. C.; PINTO, M. M.; WESTPHAL, F. S.. Influence of environmental factors favorable to the development and proliferation of mold in residencial buildings in tropical climates. Buildin and Environment, v.166, p.1-12, 2019. DOI: http://doi.org/10.1016/j.buildenv.2019.106421

A CBPC - Companhia Brasileira de Produção Científica (CNPJ: 11.221.422/0001-03) detém os direitos materiais desta publicação. Os direitos referem-se à publicação do trabalho em qualquer parte do mundo, incluindo os direitos às renovações, expansões e disseminações da contribuição, bem como outros direitos subsidiários. Todos os trabalhos publicados eletronicamente poderão posteriormente ser publicados em coletâneas impressas sob coordenação da Sustenere Publishing, da Companhia Brasileira de Produção Científica e seus parceiros autorizados. Os (as) autores (as) preservam os direitos autorais, mas não têm permissão para a publicação da contribuição em outro meio, impresso ou digital, em português ou em tradução. 